\title{
Placental Fibrinoid Deposition
}

National Cancer Institute

\section{Source}

National Cancer Institute. Placental Fibrinoid Deposition. NCI Thesaurus. Code C118147.

The presence of a small clot attached to the epithelial surface of a placental villus. 